BMJ Open

Diabetes

Research

\& Care

\title{
Can autonomy support have an effect on type 2 diabetes glycemic control? Results of a cluster randomized controlled trial
}

Qingping Yun, Ying Ji, Shenglan Liu, Yang Shen, Xuewen Jiang, Xinyi Fan, Jingnan Liu, Chun Chang (1)

\section{ABSTRACT}

Objectives To assess whether social support or autonomy support intervention for patients with type 2 diabetes can achieve glycemic control at the end of intervention, and to test whether the glycemic control effect can be maintained for a long time.

Research design and methods In this cluster randomized controlled trial, 18 community healthcare stations (CHSs) were randomized to the following: (1) usual care group (UCG) offering regular public health management services, (2) social support group (SSG) providing 3-month social support intervention based on problem solving principles, and (3) autonomy support group (ASG) offering 3-month autonomy support intervention based on self-determination theory. A total of 364 patients registered in the CHSs were enrolled into either of the three groups. The primary outcome was hemoglobin A1c (HbA1C), and secondary outcomes were diabetes self-management (DSM) behaviors. Assessment was conducted at baseline and at 3 and 6 months. Results Patients in ASG achieved better $\mathrm{HbA1c}$ reduction at the end of intervention $(0.53 \%$ or $7.23 \mathrm{mmol} / \mathrm{mol}$, $p<0.001$ ) than those in the UCG and successfully maintained it up to 6 months $(0.42 \%$ or $5.41 \mathrm{mmol} / \mathrm{mol}$, $\mathrm{p}<0.001$ ). However, patients in SSG did not experience significant change in $\mathrm{HbA} 1 \mathrm{C}$ at 3 or 6 months when compared with patients in UCG. Besides, patients in both the SSG $(0.12, p<0.05)$ and ASG $(0.22, p<0.001)$ experienced improvement in exercise at 3 months. Patients in ASG sustained improvement in exercise up to 6 months $(0.21, p<0.001)$, but those in the SSG did not.

Conclusions Autonomy support for patients with type 2 diabetes could help achieve glycemic control at the end of intervention and successfully maintain it up to 6 months. These findings indicate that autonomy support has positive long-term effects on DSM behaviors and glycemic control and can be recommended in future diabetes intervention programs.

Trial registration number ChiCTR1900024354.

permitted under CC BY-NC. commercial re-use. See rights and permissions. Published by BMJ.

School of Public Health, Peking University, Beijing, China

Correspondence to Dr Chun Chang; changchunpku@126.com

\section{INTRODUCTION}

Type 2 diabetes, along with the other three major non-communicable diseases (NCDs), accounts for over $80 \%$ of all premature NCD deaths. ${ }^{1}$ According to the most recent

\section{Significance of this study}

What is already known about this subject?

- Effective diabetes self-management (DSM) can prevent or delay complications of diabetes by glycemic control, and DSM education and support programs can help patients with diabetes engage and maintain DSM behaviors. However, the effects faded as soon as the intervention program stopped.

What are the new findings?

- Autonomy support for patients with type 2 diabetes could help achieve glycemic control at the end of 3 months of intervention and successfully maintain it up to 6 months, and autonomy support has positive long-term effects on DSM behaviors and glycemic control.

How might these results change the focus of research or clinical practice?

- To maintain DSM behaviors of patients with diabetes, autonomy support can be recommended in future diabetes intervention programs.

estimates from the International Diabetes Federation, 425 million adults aged between 20 and 79 years were estimated to have diabetes for the year 2017, and the number is expected to increase to 629 million by 2045 . $^{2}$ Diabetes has become a recognized public health concern in the 21 st century.

Effective diabetes self-management (DSM) can prevent or delay complications of diabetes by glycemic control. ${ }^{3}$ DSM behaviors, including diet, exercise, medication management and glucose monitoring, were strongly recommended by both American and Chinese national guidelines. ${ }^{45}$ To encourage patients with diabetes to adopt and maintain DSM behaviors, DSM education is the critical element of care. Given that self-management is a lifelong effort, it does not stop when patients leave the educator's office, and DSM 
support is recommended to be an ongoing process. ${ }^{4}$ In DSM support programs, social support from peers and family could help patients overcome barriers and encourage them to engage in DSM behaviors, and then work on improving DSM behaviors and clinical outcomes at the end of intervention. ${ }^{6-9}$ However, the effects faded as soon as the intervention program stopped. ${ }^{1011}$ Maintenance of sustainable DSM behaviors and glycemic control is one of the challenges of the DSM support program.

According to the self-determination theory (SDT), encouraging persistent behavior changes in patients not only requires the knowledge and skills for change but also needs patients' autonomous motivation and self-determination. $^{12} 13$ Unfortunately, many patients failed to maintain long-term behavior changes because they lacked autonomous motivation. ${ }^{12}$ With autonomous motivation, patients will perceive themselves to be the initiator of their behavior change; their healthrelated behaviors are more likely to be internalized; and thus, behavior changes will be better maintained. ${ }^{14}$ In an autonomy-supportive atmosphere, patients' autonomous motivation for change is stronger than in the situations where people feel pressured to change by others. ${ }^{15}$ Consequently, autonomy support was recommended in healthcare practice. ${ }^{1617}$ A study showed that autonomous motivation played a mediating role between perceived autonomy support and patient's DSM behaviors. ${ }^{18}$ It is likely that offering autonomy support to patients could foster a patient's autonomous motivation, which could in turn lead patients to adopt and maintain DSM behaviors, achieve better glycemic control, and maintain the effect for a longer time.

The aim of this study was to evaluate the effects of autonomy support intervention for patients with type 2 diabetes and to provide further evidence of the effects of autonomy support on long-term DSM behavior change and glycemic control. The hypotheses of this study are as follows: (1) both autonomy support and social support for patients with type 2 diabetes could achieve DSM behavior change and glycemic control at the end of intervention, and (2) the effects of autonomy support intervention could maintain the behavior change and glycemic control for a longer time.

\section{RESEARCH DESIGN AND METHODS}

\section{Design overview and participants}

The trial was performed as a cluster randomized controlled trial (RCT) with three arms (six clusters in each arm) and the observation time was 6 months. Randomization clusters were 18 community healthcare stations (CHSs) from six community healthcare centers (CHCs), Beijing, China (figure 1). Chinese CHCs are set up according to subdistrict boundaries, and each CHC has several CHSs to provide healthcare service for the neighborhood residents. Generally, patients registered in the same CHS are familiar with each other and receive the usual care from the same community doctor. In this case, the risk of contamination effects is too high to achieve the patient-level randomization. Hence, a cluster RCT was conducted, and the patients registered in the same CHS were considered as a cluster.

The potential participants were from a cross-sectional study conducted earlier, which was the pilot study of this trial. The aim of the pilot study was to identify the influencing factors of DSM behaviors. The eligible patients in this study were 18 years old and above and diagnosed with type 2 diabetes by medical institutions for at least 3 months. Patients with dementia or psychotic illnesses were excluded. Patients living alone were excluded from the trial because the intervention needed the participation of family members.

\section{Recruitment}

Recruitment was conducted by community doctors from April to May 2017. Recruitment commenced with posters

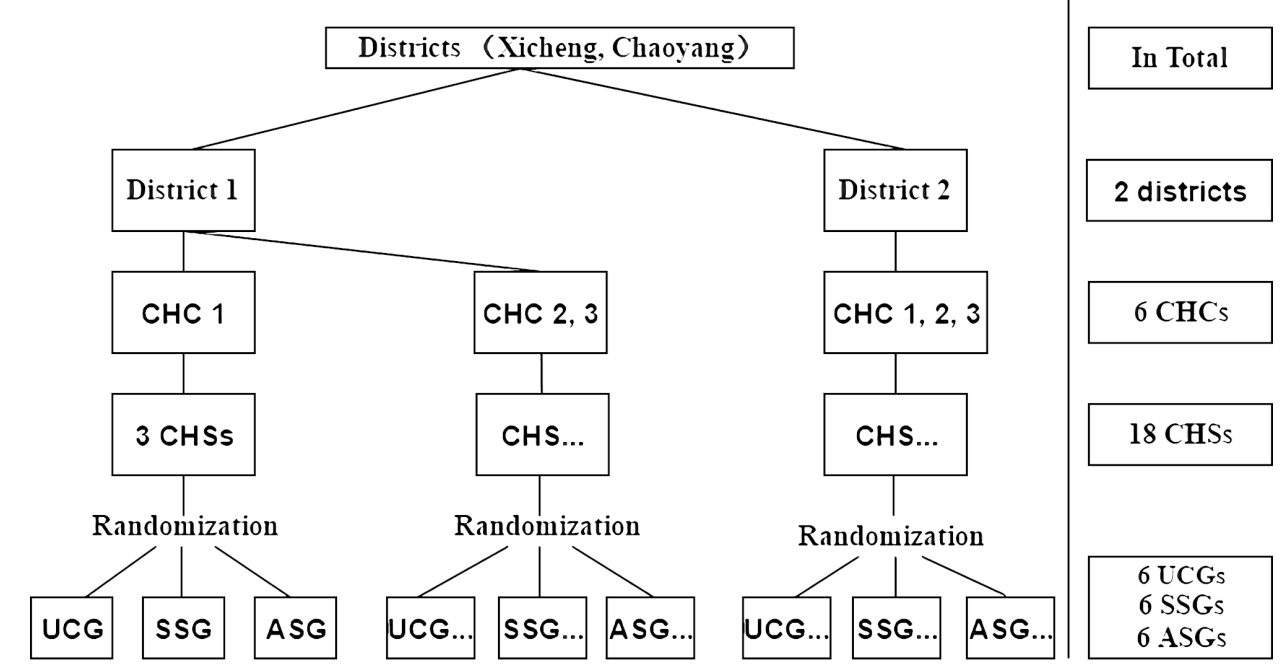

Figure 1 Site selection and randomization. ASG, autonomy support group; $\mathrm{CHC}$, community healthcare center; CHS, community healthcare station; SSG, social support group; UCG, usual care group. 
at community public places and was followed by telephone recruitment based on the patients' healthcare record. At the end of the pilot study, patients interested in the intervention study were enrolled as candidates of the trial. A random number generated by the computer was given to each candidate within a CHS. Telephone recruitment was conducted according to the order of the random number until 20 participants were recruited in each CHS. Twenty patients in the same CHS formed one cluster of the trial. All the participants in each CHS were invited to an information meeting, and the trial information was delivered, including research purpose, research content, intervention methods, benefits and risks of participating in the trial. Five patients $(1.4 \%)$ did not come to the information meeting, and nine patients $(2.5 \%)$ volunteered to participate but were not randomly selected. The specific participants in each cluster were presented in online supplementary table S1. All the participants signed the informed consent, and the trial was registered.

\section{Randomization}

To control the confounders at community level, block randomization was used. Three clusters from the same CHC were randomly allocated to usual care group (UCG), social support group (SSG) and autonomy support group (ASG) by using random digits (figure 1). Randomization took place before the recruitment. Masking was not used in participants or researchers due to the need for training and intervention. In order to control observational bias, data collectors were blinded throughout the trial.

\section{Interventions}

\section{Usual care group}

According to essential public health services for patients with type 2 diabetes in China, each patient can receive face-to-face DSM education from the community doctor every 3 months. DSM education focuses on diabetes knowledge, including diabetes diet, exercise, medication, glucose monitoring and complication prevention. Besides, each participant in UCG also received a booklet about DSM knowledge from the research team. UCG served as the control group in this study.

\section{Social support group}

On the basis of intervention in UCG, patients in SSG also received social support from the community doctors, peer leaders and family. The support interventions for SSG focused on problem solving, including eight sessions, overview of diabetes, diet, exercise, glucose monitoring, medication management, emotional management, and reinforcing the diet and exercise behavior. In each session, the community doctors conducted DSM education focusing on one topic and delivered a goal and action plan for the corresponding topic for the patients, which was then followed by the DSM support. The participants were encouraged to share their barriers and solutions in the action plan implementation, and then, a group discussion focusing on problem solving was led by peer leaders. A handbook was given to family members on how to offer support to patients with diabetes. Each session lasted $60 \mathrm{~min}$ and the whole intervention process took 3 months. Sessions were conducted once a week in the first month and twice a week in the second and third months.

\section{Autonomy support group}

The same interventions as in SSG were provided to patients in ASG, but both DSM education and support were provided using a different approach. According to the SDT, the key point of autonomy support is to foster patient motivation for DSM behaviors by meeting three basic psychological needs of the patients, including sense of autonomy, competence and relatedness. ${ }^{12} 19$ Therefore, the intervention activities were conducted as follows: (1) to satisfy the patient's sense of autonomy, the DSM education stressed why the DSM behaviors should be undertaken, and an optional list of DSM behaviors was offered to the patients; (2) the community doctor guided the patients to conduct a self-evaluation, and then set one's own special target of behavioral change and an action plan with a self-determined approach; (3) to make sure support was offered based on patients' needs, patients were encouraged to find out what kind of support they needed from their family or peers; (4) to improve competence, patients learned and reinforced the essential DSM skills in each session; when facing obstacles in conducting the action plan, they could put forward the solutions or they could seek advices from peers; and (5) to provide patients with a sense of relatedness, the doctors, family members, and peer leaders were to minimize the pressure and acknowledge patients' feelings and perspectives while providing support. A warm interpersonal environment was to be provided during the whole process. The number and topics of sessions in ASG were the same as those in SSG. The interventions for patients in the three groups are shown in online supplementary table S2.

\section{Outcomes and follow-up}

The primary outcome was hemoglobin Alc (HbAlc). The nurses working in the CHSs obtained consent and collected blood using standardized methodology, and all the blood samples were tested by a professional testing agency. The secondary outcomes were DSM behaviors, including diet, exercise, medication management and glucose monitoring. DSM behaviors were measured by Diabetes Self-management Knowledge, Attitude, and Behavior Assessment Scale (DSKAB-SF), which was developed by the Chinese Center for Disease Control and Prevention ${ }^{20}$ with the Cronbach's $\alpha$ coefficient being 0.83 among the patients with diabetes in the Chinese community. ${ }^{21}$ Seven items from DSKAB-SF (online supplementary table S3) were used to measure DSM behavior of patients with type 2 diabetes in the past 3 months, and the data were collected by questionnaires. High behavior scores represent better behaviors. The intervention phase 
lasted for 3 months, and data were collected at baseline and at 3 and 6 months.

\section{Statistical analysis}

The trial tested the main effect (HbAlc) change of UCG versus SSG, UCG versus ASG, and SSG versus ASG. The minimum necessary sample size was 94 participants for each arm based on an SD for HbAlc of $1.0 \%,{ }^{22} 2380 \%$ power to detect a difference of $0.57 \%^{24}$ in mean $\mathrm{HbAlc}$ for each main effect, intracluster correlation of $0.05^{7}$ and an average cluster size of 20 participants. Assuming a $20 \%$ loss of participants to follow-up, 113 participants were needed in each arm.

To describe and compare characteristics of participants among the three groups, continuous variables were presented as mean \pm SD and were compared with Student t-test, and categorical variables were presented as proportions and were compared with Pearson $\chi^{2}$ test. To test the effects of interventions on each follow-up time point, linear mixed model was used. Considering the cluster structure of the data, clustering variables was included in random model. In the fixed model, we included the study group, time, a study group $\times$ time interaction, the baseline variable, and the potential demographic confounders. To test the relationship between DSM behaviors and glycemic control, the multilevel regression was applied.

\section{Missing data treatment}

Imputing of missing data of the baseline were by group mean imputing, ${ }^{25}$ and this method was used to deal with two missing HbAlc data at baseline. As the linear mixed model allows the participants to be analyzed if they had data at one or more time points, ${ }^{26}$ we did not deal with the missing data at the follow-up of 3 or 6 months. To investigate the impact of missing data, we also conducted an additional sensitivity analysis on completer sample (online supplementary table S4). As there was no change in the results, the unadjusted results were reported.

We followed the Consolidated Standards of Reporting Trials (CONSORT) statement ${ }^{27}$ and its extension to clusters randomized trials ${ }^{28}$ for analyses and reporting.

\section{RESULTS}

\section{Participant flow and basic characteristics}

The CONSORT diagram (figure 2) shows the recruitment and follow-up in this study. Of the 607 participants who were invited in the cross-sectional study, 440 (72.5 $\%$ ) were interested and met the inclusion criteria in the trial. The final analysis set comprised 64 patients: 120 in UCG, 119 in SSG, and 125 in ASG. The follow-up rate was $94.5 \%$ and met expectations. The actual intracluster correlation with a mean cluster size of 20.2 was calculated

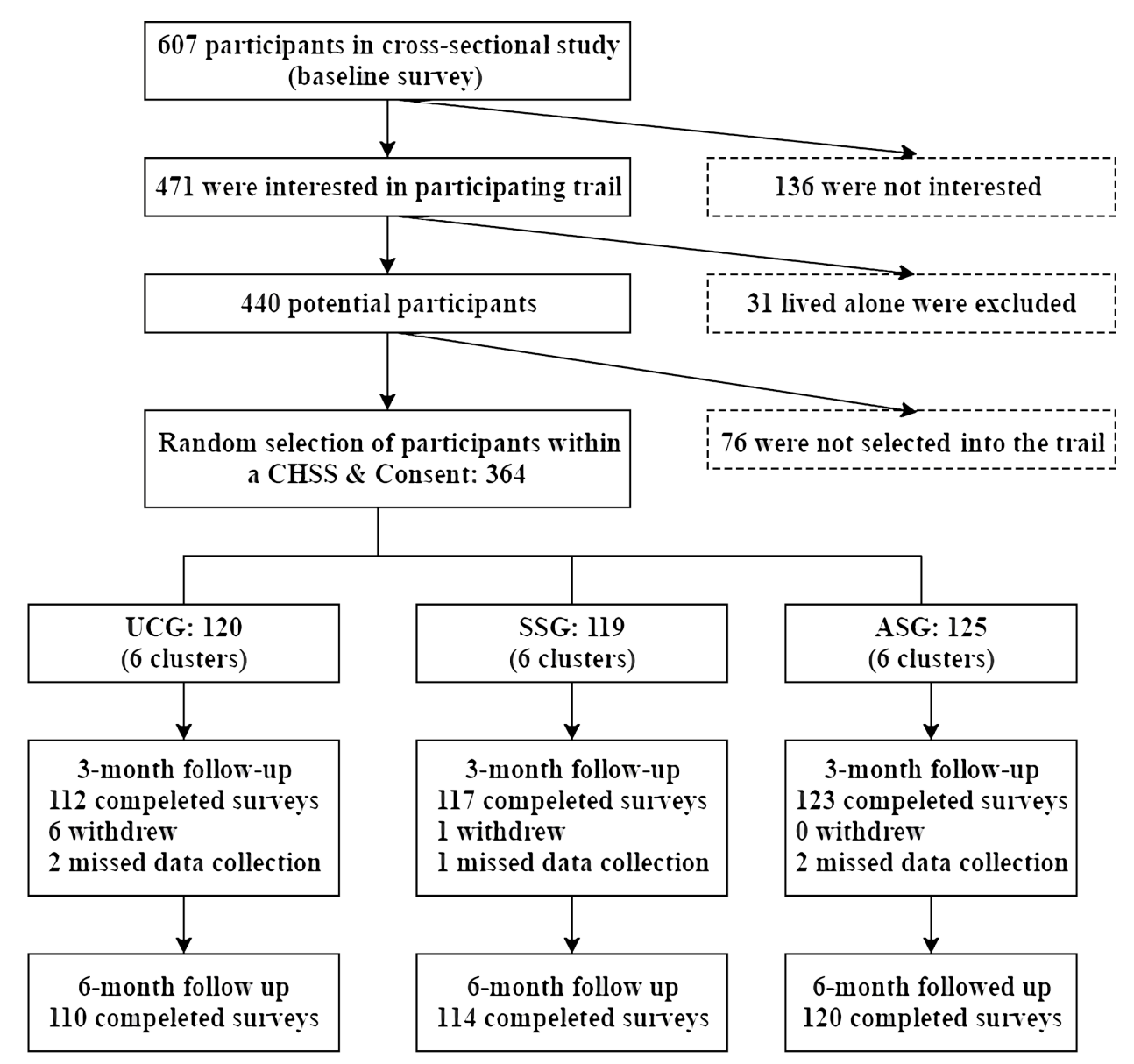

Figure 2 Recruitment and follow-up of participants. ASG, autonomy support group; CHSs, community healthcare stations; SSG, social support group; UCG, usual care group. 
to be 0.025 . Overall, the baseline characteristics were well matched among the three groups (table 1 ).

\section{Glycemic control}

The HbA1c changes in the three groups over time are shown in table 2, and HbAlc trajectories for each group are also shown in online supplementary figure 1 . The participants in SSG achieved a reduction in HbAlc at 3 months $(-0.19 \%$ or $-2.11 \mathrm{mmol} / \mathrm{mol}, \mathrm{p}<0.05)$ but failed to sustain it over 6 months. However, the clinical improvement in SSG at 3 months was not statistically different when compared with that of UCG. In ASG, participants experienced an $\mathrm{HbAlc}$ reduction in the 3-month follow-up $(-0.66 \%$ or $5.75 \mathrm{mmol} / \mathrm{mol}, \mathrm{p}<0.001)$ and successfully maintained the effect at the 6-month follow-up $(-0.50 \%$ or $4.64 \mathrm{mmol} / \mathrm{mol}, \mathrm{p}<0.001)$. The hypoglycemic effects in ASG were $-0.53 \%$ ( $-7.23 \mathrm{mmol} /$ $\mathrm{mol})$ at 3 months and $-0.42 \%(-5.41 \mathrm{mmol} / \mathrm{mol})$ at 6 months compared with those in the UCG (table 2). Similarly, hypoglycemic effects in the ASG were $-0.47 \%$ $(-5.10 \mathrm{mmol} / \mathrm{mol})$ and $-0.47 \%(-5.11 \mathrm{mmol} / \mathrm{mol})$ when compared with those in the SSG at the follow-ups of 3 and 6 months, respectively.

\section{DSM behavior change}

A slight improvement of diet behavior was found at the 6-month follow-up among the three groups, but there was no difference between different groups. The exercise score of patients in UCG experienced a decline $(-0.11$, $\mathrm{p}<0.01)$ at 3 months, while that of those in SSG did not change. The exercise score of patients in ASG improved in 3 months, and this improvement was maintained at
6 months. Compared with UCG, the exercise improvements achieved by patients in ASG at the follow-ups of 3 and 6 month were $0.22(\mathrm{p}<0.001)$ and $0.21(\mathrm{p}<0.001)$, respectively. Moreover, the exercise improvements the of the patients in ASG were statistically significant $(0.10$ and 0.20 at the follow-ups of 3 and 6 months, respectively) when compared with those of patients in the SSG. Among the three groups, the medication behavior did not change over time, and there was no difference between the groups. The glucose monitoring score of the patients in the SSG and ASG increased $0.08 \quad(p<0.001)$ and $0.09(\mathrm{p}<0.001)$, respectively. However, this change did not sustain at the 6-month follow-up and did not show a statistical significance between the groups.

To get a better understanding of the relationship between the DSM behaviors and glycemic control, a multilevel regression model of DSM behaviors on HbA1c reduction was conducted (table 3 ). The result shows that both diet and exercise behavior change were positively related to the HbAlc reduction.

\section{CONCLUSIONS}

The results tend to support hypotheses that autonomy support for patients with type 2 diabetes can achieve DSM behavior change and HbAlc reduction at the end of intervention and maintain the effects for a longer time. The results of the intergroup comparison showed that patients in ASG achieved $\mathrm{HbAlc}$ reduction and exercise improvement at the end of intervention, and successfully maintained it up to 6 months when compared with those in the UCG or SSG. Compared with patients in the UCG,

Table 1 Basic characteristics of participants

\begin{tabular}{lcccc}
\hline & UCG $(\mathbf{n}=\mathbf{1 2 0})$ & SSG (n=119) & ASG (n=125) & P value \\
\hline Gender & & & & \\
$\quad$ Male & $37(30.8)$ & $43(36.1)$ & $43(34.4)$ & 0.676 \\
\hline Female & $83(69.2)$ & $76(63.9)$ & $82(65.6)$ & \\
Age (years) & $64.68 \pm 7.41$ & $65.76 \pm 7.09$ & $64.83 \pm 7.28$ & 0.208 \\
\hline Education & & & & \\
$\quad \leq$ Junior middle school & $51(42.5)$ & $57(48.3)$ & $61(48.8)$ & \\
\hline High school & $42(35.0)$ & $41(33.9)$ & $53(42.4)$ & 0.056 \\
\hline College degree & $27(22.5)$ & $21(17.8)$ & $11(8.8)$ & \\
Marriage & & & & \\
$\quad$ Married & $105(87.5)$ & $97(81.5)$ & $98(78.4)$ & 0.165 \\
\hline Unmarried/divorce/widowed & $15(12.5)$ & $22(18.5)$ & $27(21.6)$ & \\
\hline Duration of diabetes (years) & $11.52 \pm 8.62$ & $10.55 \pm 8.31$ & $10.69 \pm 7.66$ & 0.610 \\
\hline Antihyperglycemic medication & $11(9.2)$ & $2(1.7)$ & $6(4.8)$ & 0.176 \\
\hline No medication & $81(67.5)$ & $85(71.4)$ & $94(75.2)$ & \\
\hline Diabetes tablets & $6(5.0)$ & $8(6.7)$ & $8(6.4)$ & \\
\hline Insulin treated & $22(18.3)$ & $24(20.2)$ & $17(13.6)$ & \\
\hline Insulin and tablets & & & \\
\hline
\end{tabular}

ASG, autonomy support group; SSG, social support group; UCG, usual care group. 
Table 2 Changes in $\mathrm{HbA1c}$ and diabetes self-management behaviors over time

\begin{tabular}{|c|c|c|c|}
\hline Outcome and time point & Baseline & 3 months versus baseline & 6 month versus baseline \\
\hline \multicolumn{4}{|l|}{$\mathrm{HbA1c}(\%)$} \\
\hline UCG & 7.44 (7.01 to 7.86$)$ & $-0.13(-0.34$ to 0.08$)$ & $-0.07(-0.31$ to 0.17$)$ \\
\hline SSG & 7.46 (6.89 to 8.02$)$ & $-0.19(-0.36$ to -0.03$)$ * & $-0.03(-0.27$ to 0.21$)$ \\
\hline ASG & 7.49 (7.16 to 7.81$)$ & $-0.66(-0.89 \text { to }-0.43)^{* \star \star}$ & $-0.50(-0.75 \text { to }-0.24)^{\star \star \star}$ \\
\hline SSG versus UCG & & $-0.06(-0.35$ to 0.23$)$ & $0.04(-0.31$ to 0.39$)$ \\
\hline ASG versus UCG & & $-0.53(-0.81 \text { to }-0.24)^{* * \star}$ & $-0.42(-0.77 \text { to }-0.08)^{*}$ \\
\hline$A S G$ versus $S S G$ & & $-0.47(-0.75 \text { to }-0.18)^{* *}$ & $-0.47(-0.81$ to -0.12$)$ ** \\
\hline \multicolumn{4}{|l|}{$\mathrm{HbA1c}(\mathrm{mmol} / \mathrm{mol})$} \\
\hline UCG & 57.79 (53.15 to 62.43$)$ & $-1.41(-3.67$ to 0.86$)$ & $-0.78(-3.41$ to 1.86$)$ \\
\hline SSG & 58.02 (51.85 to 60.20$)$ & $-2.11(-3.92 \text { to }-0.29)^{*}$ & $-0.32(-2.93$ to 2.29$)$ \\
\hline ASG & 58.32 (54.80 to 61.84$)$ & $-7.23(-9.72 \text { to }-4.73)^{\star \star \star}$ & $-5.41(-8.15 \text { to }-2.67)^{\star \star \star}$ \\
\hline SSG versus UCG & & $-0.63(-3.79$ to 2.53$)$ & $0.47(-3.33$ to 4.27$)$ \\
\hline ASG versus UCG & & $-5.75(-8.87 \text { to }-2.63)^{\star \star \star}$ & $-4.64(-8.39 \text { to }-0.89)^{*}$ \\
\hline ASG versus SSG & & $-5.10(-8.20 \text { to }-2.01)^{* *}$ & $-5.11(-8.88 \text { to }-1.34)^{* *}$ \\
\hline \multicolumn{4}{|l|}{ Diet } \\
\hline UCG & 1.39 (1.26 to 1.52$)$ & $0.04(-0.03$ to 0.10$)$ & $0.10(0.02 \text { to } 0.18)^{\star}$ \\
\hline SSG & 1.51 (1.36 to 1.66$)$ & $0.03(-0.04$ to 0.09$)$ & $0.07(0.01 \text { to } 0.13)^{\star}$ \\
\hline ASG & 1.52 (1.41 to 1.63$)$ & $0.09(0.02 \text { to } 0.15)^{\star \star}$ & $0.13(0.05 \text { to } 0.20)^{\star *}$ \\
\hline SSG versus UCG & & $-0.01(-0.10$ to 0.08$)$ & $-0.03(-0.13$ to 0.07$)$ \\
\hline ASG versus UCG & & $0.05(-0.04$ to 0.14$)$ & $0.03(-0.07$ to 0.13$)$ \\
\hline ASG versus SSG & & $0.06(-0.03$ to 0.15$)$ & $0.06(-0.04$ to 0.16$)$ \\
\hline \multicolumn{4}{|l|}{ Exercise } \\
\hline UCG & 1.43 (1.30 to 1.56$)$ & $-0.11(-0.17 \text { to }-0.05)^{\star *}$ & $-0.05(-0.13$ to 0.02$)$ \\
\hline SSG & 1.31 (1.13 to 1.49$)$ & $0.01(-0.05$ to 0.07$)$ & $-0.04(-0.12$ to 0.04$)$ \\
\hline ASG & $1.32(1.17$ to 1.46$)$ & $0.11(0.04 \text { to } 0.17)^{\star \star}$ & $0.16(0.08 \text { to } 0.23)^{\star \star \star}$ \\
\hline SSG versus UCG & & $0.12(0.03 \text { to } 0.21)^{\star}$ & $0.01(-0.10$ to 0.12$)$ \\
\hline ASG versus UCG & & $0.22(0.12 \text { to } 0.31)^{\star \star \star}$ & $0.21(0.10 \text { to } 0.31)^{\star \star \star}$ \\
\hline ASG versus SSG & & $0.10(0.00 \text { to } 0.19)^{\star}$ & $0.20(0.09 \text { to } 0.30)^{\star \star \star}$ \\
\hline \multicolumn{4}{|l|}{ Medication } \\
\hline UCG & 0.89 (0.82 to 0.95$)$ & $0.00(-0.03$ to 0.03$)$ & $0.00(-0.04$ to 0.04$)$ \\
\hline SSG & 0.86 (0.81 to 0.90$)$ & $-0.01(-0.03$ to 0.02$)$ & $-0.03(-0.06$ to 0.01$)$ \\
\hline ASG & 0.87 (0.81 to 0.92$)$ & $0.00(-0.04$ to 0.03$)$ & $0.02(-0.01$ to 0.06$)$ \\
\hline SSG versus UCG & & $-0.01(-0.05$ to 0.04$)$ & $-0.03(-0.07$ to 0.02$)$ \\
\hline ASG versus UCG & & $0.00(-0.05$ to 0.04$)$ & $0.02(-0.02$ to 0.07$)$ \\
\hline ASG versus SSG & & $0.00(-0.04$ to 0.04$)$ & $0.05(0.00 \text { to } 0,10)^{\star}$ \\
\hline \multicolumn{4}{|l|}{ Glucose monitoring } \\
\hline UCG & 1.42 (1.26 to 1.59$)$ & $0.03(-0.03$ to 0.10$)$ & $0.02(-0.06$ to 0.10$)$ \\
\hline SSG & 1.32 (1.12 to 1.52$)$ & $0.08(0.03 \text { to } 0.14)^{\star \star}$ & $0.05(-0.03$ to 0,12$)$ \\
\hline ASG & 1.29 (1.18 to 1.41$)$ & $0.09(0.02 \text { to } 0.16)^{\star *}$ & $0.08(0.00$ to 0.16$)$ \\
\hline SSG versus UCG & & $0.05(-0.04$ to 0.14$)$ & $0.01(-0.08$ to 0.14$)$ \\
\hline ASG versus UCG & & $0.06(-0.03$ to 0.15$)$ & $0.06(-0.05$ to 0.17$)$ \\
\hline ASG versus SSG & & $0.01(-0.08$ to 0.09$)$ & $0.03(-0.08$ to 0.14$)$ \\
\hline
\end{tabular}

Data were estimated for means $(95 \% \mathrm{Cl})$. The data of within-group were adjusted for baseline value, and the data of between-group were adjusted for baseline and basic characteristics. $P$ values for within-group were different from the given time point to baseline; $p$ values for between-group difference score were relative to baseline from the linear mixed model.

${ }^{*} \mathrm{P}<0.05,{ }^{* *} \mathrm{P}<0.01,{ }^{* \star *} \mathrm{P}<0.001$.

ASG, autonomy support group; HbA1c, hemoglobin A1c; SSG, social support group; UCG, usual care group. 
Table 3 Multilevel regression model of the effects of diabetes self-management behaviors on hemoglobin A1c reduction

\begin{tabular}{lcl}
\hline DSM behaviors & B $\mathbf{( 9 5 \%} \mathbf{C l})$ & P value \\
\hline Diet & $0.37(0.01$ to 0.75$)$ & 0.044 \\
Exercise & $0.43(0.09$ to 0.76$)$ & 0.013 \\
Medication & $-0.47(-1.24$ to 0.31$)$ & 0.236 \\
Glucose monitoring & $-0.23(-0.56$ to 0.11$)$ & 0.185 \\
\hline
\end{tabular}

Adjusted for the demographic and medication variables.

DSM, diabetes self-management.

patients in SSG did not experience HbAlc reduction at 3 or 6 months. In addition, the result from the regression model shows that there is a positive relationship between DSM behavior change and HbA1c reduction, which indicates that the effects of interventions on glycemic control might through DSM behavior change.

Patients in ASG experienced exercise improvement and HbAlc reduction at the end of intervention and maintained the effects at 6 months. These changes could be explained by the SDT model of health behavior change. ${ }^{12}$ In the autonomy support interventions, patients experienced a feeling of autonomy, competence and relatedness, and their motivation for health-related behaviors was internalized, which led patients to engage and maintain the DSM behaviors, and thus achieve glycemic control. The HbAlc reduction and exercise improvement in ASG could be maintained until 6 months, and this lasting effectiveness might be due to the enhancement of the patient's autonomous motivation. In healthcare, patients perceived autonomy support can predict autonomous motivation to participate in medical treatment, ${ }^{13}$ and this autonomous participation will maintain patients' behavior change and achieve long-term positive health outcome. ${ }^{13} 29$ Autonomy support interventions were applied in the treatment of other health issues (such as improving physical activity ${ }^{30}$ smoking cessation, ${ }^{31}$ and substance abuse treament, ${ }^{32}$ and were found to have long-term effects. When offering autonomy support for patients with type 2 diabetes, similar longterm effects were also found in this study. Hence, pieces of evidence from current and previous studies illustrate that autonomy support has a unique effect in maintaining long-term medical treatment.

However, compared with UCG, patients in SSG experienced exercise improvement at the end of intervention but failed to maintain it at 6 months. Besides, no statistically significant HbA1c reduction was found in patients in SSG. These results indicate that social support might have a short-term effect on DSM behavior change, and it is hard to maintain the effect over a longer period of time. Similar results were also found in other communitybased DSM support intervention studies. ${ }^{10} 33$

In the current study, results from regression analysis showed that both diet and exercise behavior modification were related to $\mathrm{HbA1c}$ reduction, which indicated that the interventional effects on glycemic control might be mediated through DSM behaviors, and this mediating effect was supported by a previous study. ${ }^{14}$ Four DSM behaviors were observed in this study; only improvement in exercise was found. Thus, the glycemic control effects might be beneficial from exercise improvement. A previous study showed that the intervention program based on SDT could promote exercise ${ }^{18} 34$ and diet behavior, ${ }^{35}$ but diet behavior improvement effect was not found in the current study. One of the reasons could probably be a lack of family diet support. Diabetic diet needs the cooperation of families, such as a family diabetes meal plan. ${ }^{9}$ As family training was only arranged during the first session, family diet support for diabetes might not be enough in this study.

Some limitations need to be mentioned for this study. First, the trial was conducted in Chinese urban communities with high economic status, so the community doctors were likely to have higher professional competence to conduct the interventions. Professional ability of community doctors is an influencing factor of diabetes healthcare quality. ${ }^{36}$ When this intervention is applied in rural areas, training for community doctors must be emphasized. Second, this kind of community-based autonomy support intervention is better suited for older individuals. The average age of current sample was $65.14 \pm 7.23$ years old and $75 \%$ of them were older than 60 years. Participants who are younger than 60 years are more likely to be lost to follow-up because they have to work and might miss the intervention session. Third, we failed to collect the individual intervention data, so the intervention dosage effect should be explored in a future study.

This cluster RCT showed that autonomy support for patients with type 2 diabetes could achieve improvement in exercise behaviors and glycemic control at the end of intervention, and these effects could be successfully maintained up to 6 months. These findings also indicate that autonomy support can help maintain glycemic control effect for a longer time, which can be recommended in future diabetes intervention programs.

Acknowledgements The authors thank the staff from the Center for Disease Control and Prevention in Chaoyang and Dongsheng Districts, Beijing, China, who gave a lot of support in the implementation of this research. The authors also thank the patients and their families who participated in this study.

Contributors SL and CC conceived of the study concept and design. QY, YJ and YS analyzed data. QY wrote the manuscript, and YJ contributed to the discussion. XJ and $\mathrm{XF}$ reviewed the manuscript. XJ, XF and $\mathrm{JL}$ took responsibility for collecting the data and quality control of the data. CC and QY are the guarantors for this study, had full access to all the data and took the responsibility for the integrity of the data and the accuracy of the data analysis.

Funding The authors have not declared a specific grant for this research from any funding agency in the public, commercial or not-for-profit sectors.

Competing interests None declared.

Patient consent for publication Not required.

Ethics approval Ethics approval (IRB00001052-17017) was obtained from the institutional review board of Peking University Health Science Center.

Provenance and peer review Not commissioned; externally peer reviewed. 
Data availability statement Data are available upon reasonable request. The raw data of the current study cannot be shared at this time because the data is part of an ongoing study, but the data are available from the corresponding author on reasonable request.

Open access This is an open access article distributed in accordance with the Creative Commons Attribution Non Commercial (CC BY-NC 4.0) license, which permits others to distribute, remix, adapt, build upon this work non-commercially, and license their derivative works on different terms, provided the original work is properly cited, appropriate credit is given, any changes made indicated, and the use is non-commercial. See: http://creativecommons.org/licenses/by-nc/4.0/.

ORCID iD

Chun Chang http://orcid.org/0000-0001-7863-3316

\section{REFERENCES}

1 GBD 2015 Risk Factors Collaborators. Global, regional, and nationa comparative risk assessment of 79 behavioural, environmental and occupational, and metabolic risks or clusters of risks, 1990-2015: a systematic analysis for the global burden of disease study 2015 . Lancet 2016;388:1659-724.

2 International Diabetes Federation (IDF). IDF diabetes atlas. 8th edn. Brussels: International Diabetes Federation, 2017.

3 Chrvala CA, Sherr D, Lipman RD. Diabetes self-management education for adults with type 2 diabetes mellitus: a systematic review of the effect on glycemic control. Patient Educ Couns 2016;99:926-43.

4 Beck J, Greenwood DA, Blanton L, et al. 2017 national standards for diabetes self-management education and support. Diabetes Educ 2017:43:449-64.

5 Chinese Diabetes Society. Guidelines for the prevention and control of type 2 diabetes in China (2017 edition). Chin J Pract Inter Med 2018;38:292-344

6 Philis-Tsimikas A, Walker C, Rivard L, et al. Improvement in diabetes care of underinsured patients enrolled in project dulce: a communitybased, culturally appropriate, nurse case management and peer education diabetes care model. Diabetes Care 2004;27:110-5.

7 Simmons D, Prevost AT, Bunn C, et al. Impact of community based peer support in type 2 diabetes: a cluster randomised controlled trial of individual and/or group approaches. PLoS One 2015;10:e0120277.

8 Pamungkas RA, Chamroonsawasdi K, Vatanasomboon P. A systematic review: family support integrated with diabetes selfmanagement among uncontrolled type II diabetes mellitus patients. Behav Sci 2017;7:62-77.

9 Adebola OG. Type 2 diabetes: an evidence-based approach to its management by the family practitioner. Contin Med Educ 2006;24:568.

10 Lorig K, Ritter PL, Villa FJ, et al. Community-based peer-led diabetes self-management: a randomized trial. Diabetes Educ 2009;35:641-51.

11 Tang TS, Funnell M, Sinco B, et al. Comparative effectiveness of peer leaders and community health workers in diabetes selfmanagement support: results of a randomized controlled trial. Diabetes Care 2014;37:1525-34.

12 Ryan R, Patrick H, Deci E, et al. Facilitating health behavior change and its maintenance: interventions based on Self-Determination theory. Eur Health Psychol 2008;10:2-5.

13 Williams GC, Freedman ZR, Deci EL. Supporting autonomy to motivate patients with diabetes for glucose control. Diabetes Care 1998;21:1644-51

14 Williams GC, McGregor HA, Zeldman A, et al. Testing a selfdetermination theory process model for promoting glycemic control through diabetes self-management. Health Psychol 2004;23:58-66.

15 Ryan RM, Deci EL. Self-determination theory and the facilitation of intrinsic motivation, social development, and well-being. Am Psychol 2000;55:68-78.
16 Williams GC, Niemiec CP, Patrick H, et al. The importance of supporting autonomy and perceived competence in facilitating longterm tobacco abstinence. Ann Behav Med 2009;37:315-24.

17 Silva MN, Markland D, Carraça EV, et al. Exercise autonomous motivation predicts 3-yr weight loss in women. Med Sci Sports Exerc 2011;43:728-37.

18 Koponen AM, Simonsen N, Suominen S. Determinants of physical activity among patients with type 2 diabetes: the role of perceived autonomy support, autonomous motivation and self-care competence. Psychol Health Med 2017;22:332-44.

19 Patrick H, Williams GC. Self-determination theory: its application to health behavior and complementarity with motivational interviewing. Int J Behav Nutr Phys Act 2012;9:18.

20 Wang W, Wu Y, Feng N, et al. [Study on developing a Brief Version of Diabetes Self-management Knowledge, Attitude, and Behavior Assessment Scale (DSKAB-SF)]. Zhonghua Yu Fang Yi Xue Za Zhi 2016;50:50-5.

21 Wu YZ, Wang WJ, Feng NP, et al. [Validity, reliability, and acceptability of the brief version of the self-management knowledge, attitude, and behavior assessment scale for diabetes patients]. Zhonghua Yu Fang Yi Xue Za Zhi 2016;50:589-93.

22 Xie B, Ye X-li, Sun Z-lin, et al. Peer support for patients with type 2 diabetes in rural communities of China: protocol for a cluster randomized controlled trial. BMC Public Health 2014;14:747.

23 Prezio EA, Balasubramanian BA, Shuval K, et al. Evaluation of quality improvement performance in the community diabetes education (code) program for uninsured Mexican Americans: results of a randomized controlled trial. Am J Med Qual 2014;29:124-34.

24 Qi L, Liu Q, Qi X, et al. Effectiveness of peer support for improving glycaemic control in patients with type 2 diabetes: a meta-analysis of randomized controlled trials. BMC Public Health 2015;15:471.

25 Taljaard M, Donner A, Klar N. Imputation strategies for missing continuous outcomes in cluster randomized trials. Biom $\mathrm{J}$ 2008;50:329-45

26 Lamberton D, Lapeyre B, Ke W. Linear mixed models: a practical guide using statistical software; 2013

27 Moher D, Hopewell S, Schulz KF, et al. CONSORT 2010 explanation and elaboration: updated guidelines for reporting parallel group randomised trials. BMJ 2010;340:c869-c69.

28 Campbell MK, Piaggio G, Elbourne DR, et al. Consort 2010 statement: extension to cluster randomised trials. BMJ 2012;345:e5 661-e61.

29 Williams G, Deci E, Ryan R. Building healthcare partnerships by supporting autonomy: promoting maintained behaviour change and positive health outcomes. Rochester, NY: University of Rochester Press, 1998.

30 Fortier MS, Duda JL, Guerin E, et al. Promoting physical activity: development and testing of self-determination theory-based interventions. Int J Behav Nutr Phys Act 2012;9:20-14.

31 Pesis-Katz I, Williams GC, Niemiec CP, et al. Cost-effectiveness of intensive tobacco dependence intervention based on selfdetermination theory. Am J Manag Care 2011;17:e393.

32 Zeldman A, Ryan RM, Fiscella K. Motivation, autonomy support, and entity beliefs: their role in Methad. J Soc Clin Psychol 2005;23.

33 Samuel-Hodge CD, Keyserling TC, Park S, et al. A randomized trial of a church-based diabetes self-management program for African Americans with type 2 diabetes. Diabetes Educ 2009;35:439-54.

34 Koponen AM, Simonsen N, Suominen SB. Success in weight management among patients with type 2 diabetes: do perceived autonomy support, autonomous motivation, and self-care competence play a role? Behav Med 2018;44:151-9.

35 Leblanc V, Bégin C, Hudon A-M, et al. Effects of a nutritional intervention program based on the self-determination theory and promoting the Mediterranean diet. Health Psychol Open 2016;3:205510291562209.

36 Goderis G, Borgermans L, Mathieu C, et al. Barriers and facilitators to evidence based care of type 2 diabetes patients: experiences of general practitioners participating to a quality improvement program. Implement Sci 2009;4:41. 